\title{
Business Size Extension and Zipf's Law: The Case of Top Corporate Groups in Taiwan
}

\author{
Yun-Huan Lee ${ }^{1} \&$ Chih-Hsiang $\mathrm{Hsu}^{1}$ \\ ${ }^{1}$ Department of Finance, Ming Chuan University, Taipei, Taiwan \\ Correspondence: Chih-Hsiang Hsu, Department of Finance, Ming Chuan University, Taipei, Taiwan. Tel: \\ 886-228-824-564 ext. 2628. E-mail: chadhsu@mail.mcu.edu.tw
}

Received: January 13, 2014

Accepted: February 13, $2014 \quad$ Online Published: March 21, 2014

doi:10.5539/ijbm.v9n4p124

URL: http://dx.doi.org/10.5539/ijbm.v9n4p124

\begin{abstract}
This paper studies the upper tail distribution of the business group size in Taiwan. Our empirical study was based on the top 100 Taiwan business groups ranked in annual revenue, asset and employees during 2003 to 2009. We find that the group size distribution is fatter-tailed and gradually deviated from the Zipf's Law. Moreover, the law of proportional effect is violated.Specifically, our result shows that the larger business accompanies larger growth rate.
\end{abstract}

Keywords: group size, Zipf distribution, growth rate

\section{Introduction}

Gilbrat's rule of proportional growth states that the growth rate of a firm is independent to its size. This leads to a lognormal firm size distribution and its upper tail taking the shape of Zipf's distribution. Using data from different industries, different countries, and different firm size measures, this rule has been examined in a spate of literature for a long time (For a survey, see Sutton, 1997). This rule, however, is still debatable when examining empirical evidences.

Some researchers show that the real firm size of big companies is smaller than Gilbrat's prediction. According to information of U.S. publicly traded firms from 1988 to 1997, Axtell (2001) suggests that the firm size follows the Zipf distribution except for the extra big firms. By using data of US manufacturing industries, Hall (1987) argues that the growth rate can be decreasing with the size of a firm. Consequently, firm size distribution is not closing lognormal but rather more concentrated. Stanley et al. (1995) shows that the log-normal distribution fits US firms' size, but in the upper tail. Specifically, their result suggests the upper tail is relatively thin. This finding is also confirmed by Fujiwara et al. (2004) by studying the data of France and UK.

On the other hand, some research finds that the upper tail of the firm size distribution is fatter than log-normal. Kang et al. (2011) studied the inequality of the scale of Korean firms and shows that the top companies are relatively large to the log-normal and this inequality is quite severe prior to the 1997 financial crisis. Hernandes-Perez et al. (2006) suggest that the log-normal distribution describes the data of developed countries better than that of developing ones.

To summarize the previous research, Gilbrat's law fits the firm size distribution well for many developed countries, although some find that there is a thinner upper tail. Conversely, for most of the emerging economies, the firm size distribution is more dispersed and is with an upper tail which is fatter than log-normal. Using the data of Taiwan, this study attempts to explain this difference with the consideration of the culture of business group in emerging economies.

The management and operation of a firm are usually getting better as its scale is getting larger. Based on the view point of comparative advantage, Faria's (2008) model suggests that a firm with high managerial skills has a higher opportunity cost to developing a new technology than one with lower managerial skills. Thus, during an age where technology transforms quickly, many large companies will not invest on research and development of new products. Instead, they merge smaller companies to quickly enter a new product space. Additionally, besides using mergers to quickly increase growth, many emerging market companies will also choose to enter strategic alliances with smaller companies to achieve the same desired results. This is usually done by taking a minority stake in the smaller company or through a share swap. Under this structure, many independent 
companies come to form a larger entity, which we usually refer to as business groups.

The popularity of business groups could affect the firm size distribution to not follow Gilbrat's law. If a company chooses to invest its earnings in other companies, a company's growth will only be reflected on its assets, but neither on the number of employees nor its revenue. Consequently, we would not have a log-normal distribution if we use employee number or revenue to measure a company's size. Specifically, because the large companies do more likely to transfer their investments, this deviation occurs especially on the upper tail of the distribution.

In reality, in many emerging economies, many companies use a business group structure to work with others, as one entity. Therefore, it is reasonable for us to regard all of the group members as one business entity. This research uses business group as the unit to measure the business size and to look into the size distribution of Taiwanese business groups.

The rest of this paper is organized as follows. Section 2 introduces the methodology for assessing the distribution of business group sizeinTaiwan. Section 3 applies the descriptive statistics and Zipf plot to top 100 business groups recorded by CCIS Company from 2004 to 2009. Finally, a brief discussion is given in Section 4.

\section{Data and Methodology}

\subsection{The Data}

One area of the difficulty for this research is on how to define a business group. Many academics have tried to define and explain a business group, such as Leff (1978) and Khanna and Ravkin (2001) among others. (Note 1) These definitions, however, are often abstract and not clearly defined. Our research uses the concrete definition by China Credit Information Service (CCIS) to help determine Taiwan's business groups. According to the standards of CCIS, a business group must satisfy one or more of the followingseven, objective conditions for us to recognize it as such, before we scrutinize it for other subjective conditions.

(1) The shares held by investment companies are more than $50 \%$. Or mutual investment between companies and each hold more than $33 \%$ of shares in each other. Or less than the above ratio, but in fact, holds large portion of the company's shares and has direct control.

(2) The company and the core company have more than half of the same shareholders or investors.

(3) More than half of the board of directors, independent directors, and executive shareholders, are the same at both the company and the core company.

(4) The company and the core company have more than half of the directors, independent directors, executive shareholders, shareholders that represent the company, and the general manager who are spouses or relatives in a third degree relationship.

(5) The company, based on the No. 7 communique of the accounting standards, must submit a consolidated financial report with the core company or one of its subsidiary company.

(6) The company and the core company are under the same supervision from a supervisory entity.

(7) The chairman or general manager of the company is the chairman or general manager of the core company. And the company business address is the same as the core company.

According to the above classification, 100 to 300 Business Groups are identified. Our research uses asset, employee, and revenue to measure and carry on statistical research.

\subsection{Method}

Suppose that the random variable $\mathrm{X}$ (asset, revenue and employees) isthe size ofenterprise groups and $\mathrm{F}_{\mathrm{X}}(\mathrm{x})$ is the distribution of $\mathrm{X}$. Let $\left(\mathrm{x}_{1}, \ldots, \mathrm{x}_{\mathrm{n}}\right)$ be a set of observations of $\mathrm{X}, \mathrm{n}$ is number of enterprise groups. $\left(\mathrm{x}_{(1)}, \ldots, \mathrm{x}_{(\mathrm{n})}\right)$ is a descending order array of $\left(\mathrm{x}_{1}, \ldots, \mathrm{x}_{\mathrm{n}}\right)$. As a result of $\mathrm{i} / \mathrm{n}=1-\mathrm{F}\left(\mathrm{x}_{(\mathrm{i})}\right), \mathrm{i}=1, \ldots, \mathrm{n}, \mathrm{F}(\cdot)$ is an empirical distribution of $\mathrm{X}$,

$$
\log (\mathrm{i})=\log \left(1-\mathrm{F}\left(\mathrm{x}_{(\mathrm{i})}\right)\right)+\log (\mathrm{n}) .
$$

Equation (1) points out the log of the rank can be transformed to the distribution function. However, many literatures show that the distribution of firm size follow log-normal except for top firms. When $\log (\mathrm{X})$ follows normal distribution with mean $\mu$ and variance $\sigma^{2}$, i.e. X follows log-normal distribution. Equation (1) can be written as 


$$
\log (\mathrm{i})=\log \left(1-\Phi\left(\frac{\log \left(\mathrm{x}_{(\mathrm{i})}-\mu\right)}{\sigma}\right)\right)+\log (\mathrm{n}),
$$

Where $\Phi$ is the standard normal cumulative distribution, so

$$
\log \left(\mathrm{x}_{(\mathrm{i})}\right)=\sigma \Phi^{-1}\left(1-\frac{\mathrm{e}^{\log (\mathrm{i})}}{\mathrm{n}}\right)+\mu
$$

Zipf plot is draw by $\log \left(\mathrm{x}_{(\mathrm{i})}\right)$ in equation (2) and company size. With the aid of the Zipf plot, it accentuates the upper tail of the distribution and therefore makes it easier to detect deviations in the upper tail from the theoretical prediction of a particular distribution; the Zipf plot is particularly useful for analyzing this question (cf. Stanley et al., 1995). The data series used are those of the non-financialcompanies listed on Taiwan stock markets. Figure 1 shows a histogram of the log of asset, it seems to fit the log-normal reasonable well. However, Zipf plot in Figure 2 shows the actual Zipf plot lies roughly above the theoretical plot of the largest 100 firms. Therefore, Gibrat's law is not satisfied in Taiwan.

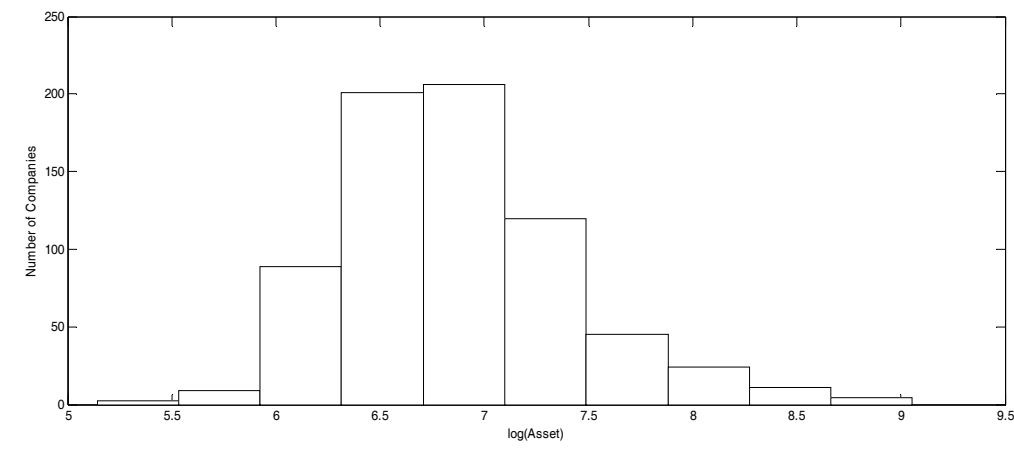

Figure 1. Distribution of firm size in 2010

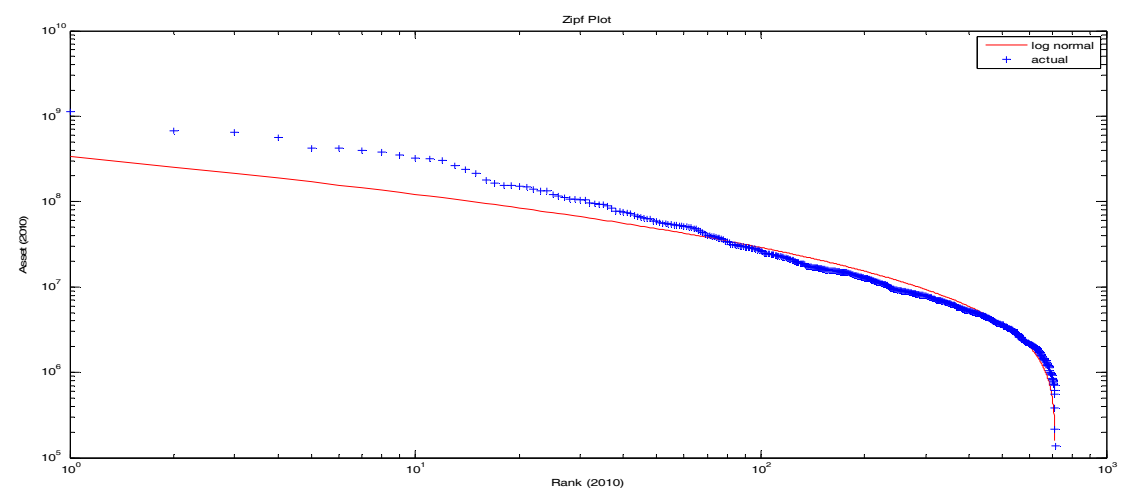

Figure 2. Zipf plot of firm size

Zhang et al. (2009) and Kang et al. (2011) pointed out the distribution of top firms approximateParetodistribution (Power-law distribution, Zipf distribution),

$$
\mathrm{P}(\mathrm{X}>x) \sim \mathrm{X}^{-1 / \beta},
$$

where the exponent of $1 / \beta$ is called Pareto index. The larger the value of $\beta$, the greater the relative size of a large firm (high ranked firm) as comparedwith a smaller firm (low ranked firm). When $\beta \rightarrow 1$, this special case of the Pareto distribution is known as the Zipf law. (Note 2) Gabaix et al. (2007) proposed a modified least square estimation as below to estimate the Pareto index

$$
\log (X)=\alpha-\beta \log (i-0.5)
$$


In the equation (3), the coefficient $\beta$ is called the Zipf's coefficient and can be used to measure the dispersion across the firm sizes for the large firms.

\section{Empirical Results}

This empirical study was based on the top 100 Taiwan business groups ranked in annual revenue, asset and employees, respectively. The source of the datawas the CCIS for the period between 2004 and 2009. Table 1 reports the descriptive statistics of group sizes for the years between 2004 and 2009 and shows that the average group size increases as time increases. We also find that the standard deviation for the size of groups increases over time and it increases more rapidly than the mean size. Moreover, the growth rates of the mean size of top 10 large groups are larger than those of whole the sample in most periods. These empirical evidences suggest that the larger groups grow more quickly than smaller ones, and this result shows that the law of proportional effects is not support in Taiwan's case.

Table 1. Descriptive statistics of group size distribution

\begin{tabular}{|c|c|c|c|c|c|c|c|}
\hline & & 2004 & 2005 & 2006 & 2007 & 2008 & 2009 \\
\hline \multirow{9}{*}{ asset } & Obs. & 79 & 79 & 79 & 81 & 82 & 80 \\
\hline & Mean & $1.90 \mathrm{E}+08$ & $2.19 \mathrm{E}+08$ & $2.07 \mathrm{E}+08$ & $2.32 \mathrm{E}+08$ & $2.28 \mathrm{E}+08$ & $2.52 \mathrm{E}+08$ \\
\hline & Growth rate & 0.1596 & 0.1532 & -0.0544 & 0.1218 & -0.0205 & 0.1085 \\
\hline & Median & $1.12 \mathrm{E}+08$ & 97336617 & 96118073 & $1.13 \mathrm{E}+08$ & $1.04 \mathrm{E}+08$ & $1.12 \mathrm{E}+08$ \\
\hline & Maximum & $1.68 \mathrm{E}+09$ & $1.80 \mathrm{E}+09$ & $2.13 \mathrm{E}+09$ & $2.46 \mathrm{E}+09$ & $2.35 \mathrm{E}+09$ & $2.56 \mathrm{E}+09$ \\
\hline & Minimum & 31777091 & 34280233 & 33998806 & 32982188 & 32220811 & 37332174 \\
\hline & Std. Dev. & $2.29 \mathrm{E}+08$ & $2.94 \mathrm{E}+08$ & $2.89 \mathrm{E}+08$ & $3.47 \mathrm{E}+08$ & $3.36 \mathrm{E}+08$ & $3.88 \mathrm{E}+08$ \\
\hline & Top 10 mean & $6.08 \mathrm{E}+08$ & $7.75 \mathrm{E}+08$ & $7.52 \mathrm{E}+08$ & $9.13 \mathrm{E}+08$ & $9.09 \mathrm{E}+08$ & $1.01 \mathrm{E}+09$ \\
\hline & Growth rate & 0.2146 & 0.2755 & -0.0302 & 0.2151 & -0.0042 & 0.1054 \\
\hline \multirow{8}{*}{ revenue } & Mean & $1.35 \mathrm{E}+08$ & $1.56 \mathrm{E}+08$ & $1.78 \mathrm{E}+08$ & $2.05 \mathrm{E}+08$ & $2.10 \mathrm{E}+08$ & $2.10 \mathrm{E}+08$ \\
\hline & Growth rate & 0.2493 & 0.1514 & 0.1455 & 0.1497 & 0.0249 & -0.0014 \\
\hline & Median & 67011366 & 72225019 & 73458147 & 80671769 & 82671599 & 79814494 \\
\hline & Maximum & $1.28 \mathrm{E}+09$ & $1.46 \mathrm{E}+09$ & $1.61 \mathrm{E}+09$ & $2.03 \mathrm{E}+09$ & $2.31 \mathrm{E}+09$ & $2.63 \mathrm{E}+09$ \\
\hline & Minimum & 9800927 & 10403526 & 11203232 & 8734351 & 6711701 & 7443695 \\
\hline & Std. Dev. & $1.79 \mathrm{E}+08$ & $2.22 \mathrm{E}+08$ & $2.71 \mathrm{E}+08$ & $3.38 \mathrm{E}+08$ & $3.66 \mathrm{E}+08$ & $3.75 \mathrm{E}+08$ \\
\hline & Top 10 mean & $4.68 \mathrm{E}+08$ & $5.77 \mathrm{E}+08$ & $7.10 \mathrm{E}+08$ & $8.80 \mathrm{E}+08$ & $9.29 \mathrm{E}+08$ & $9.40 \mathrm{E}+08$ \\
\hline & Growth rate & 0.2902 & 0.2313 & 0.2319 & 0.2385 & 0.0559 & 0.0118 \\
\hline \multirow{8}{*}{ employee } & Mean & 19458.84 & 24291.9 & 27821.53 & 34215.22 & 32999 & 37753.75 \\
\hline & Growth rate & 0.4958 & 0.2484 & 0.1453 & 0.2298 & -0.0355 & 0.1441 \\
\hline & Median & 10047 & 10726 & 11330 & 12322 & 12240 & 12337 \\
\hline & Maximum & 269405 & 289867 & 469906 & 657707 & 579586 & 768879 \\
\hline & Minimum & 632 & 599 & 332 & 385 & 304 & 344 \\
\hline & Std. Dev. & 37327.7 & 45949.38 & 63044 & 82377.65 & 75270.69 & 94576.68 \\
\hline & Top 10 mean & $8.43 \mathrm{E}+04$ & $1.06 \mathrm{E}+05$ & $1.30 \mathrm{E}+05$ & $1.67 \mathrm{E}+05$ & $1.60 \mathrm{E}+05$ & $1.89 \mathrm{E}+05$ \\
\hline & Growth rate & 0.8046 & 0.2538 & 0.2308 & 0.2848 & -0.0405 & 0.1791 \\
\hline
\end{tabular}

Discription: This table presents the descriptive statistics of group sizes in the scale of asset, revenue, and the number of employee, respectively. The sample period is from 2004 to 2009.

Table 2 reports the estimates of Zipf's coefficient $\beta$ in equation (3), theircorresponding standard errors, and the coefficient of determination $\left(\mathrm{R}^{2}\right)$, for the chosen seven years. Although there is no significant evidence to show that the size of the groups deviate from the Zipf distribution, it is trivial that the coefficient gradually increases over time. This result is consistent to the implication that we suggest from Table 1, and finds that the group size distribution got more and more dispersed during the research period. 
Table 2. Estimation results and the KS test for goodness of fit of groups

\begin{tabular}{lllll}
\hline & year & $\hat{\beta}$ & $\mathrm{R}^{2}$ & s.e. \\
\hline 2003 & 0.7846 & 0.9007 & 0.1264 \\
2004 & 0.8571 & 0.8779 & 0.1363 \\
asset & 2005 & 0.9291 & 0.8966 & 0.1478 \\
& 2006 & 0.9516 & 0.9025 & 0.1514 \\
& 2007 & 1.0033 & 0.9103 & 0.1576 \\
& 2008 & 1.0116 & 0.9075 & 0.1579 \\
& 2009 & 0.9955 & 0.9198 & 0.1574 \\
\hline & 2003 & 0.9811 & 0.8248 & 0.1581 \\
revenue & 2004 & 0.9726 & 0.8517 & 0.1547 \\
& 2005 & 0.9953 & 0.8795 & 0.1583 \\
& 2006 & 1.0745 & 0.8772 & 0.1709 \\
& 2007 & 1.1031 & 0.8939 & 0.1733 \\
& 2008 & 1.1883 & 0.8671 & 0.1855 \\
& 2009 & 1.1905 & 0.8838 & 0.1882 \\
\hline 2003 & 0.9895 & 0.8626 & 0.1594 \\
2004 & 1.0658 & 0.8769 & 0.1695 \\
2005 & 1.0886 & 0.8711 & 0.1732 \\
& 2006 & 1.1495 & 0.8488 & 0.1828 \\
& 2007 & 1.2095 & 0.8604 & 0.1900 \\
& 2008 & 1.2802 & 0.8232 & 0.1999 \\
& 2009 & 0.8501 & 0.2039 \\
\hline
\end{tabular}

Discription: Table 2 reports the estimates of Zipf's coefficients in equation (3), theircorresponding standard errors, and the coefficient of determination $\left(\mathrm{R}^{2}\right)$ for the sample years from 2004 to 2009.

Figure 3 to Figure 5 show the log-log plots of the rank distribution of group size during 2003 to 2009. The results obviously show that the sizes of the large groups deviate from the Zipf's distribution. This finding supports our inference that the large corporate groups grow more quickly than small and medium sized enterprises.

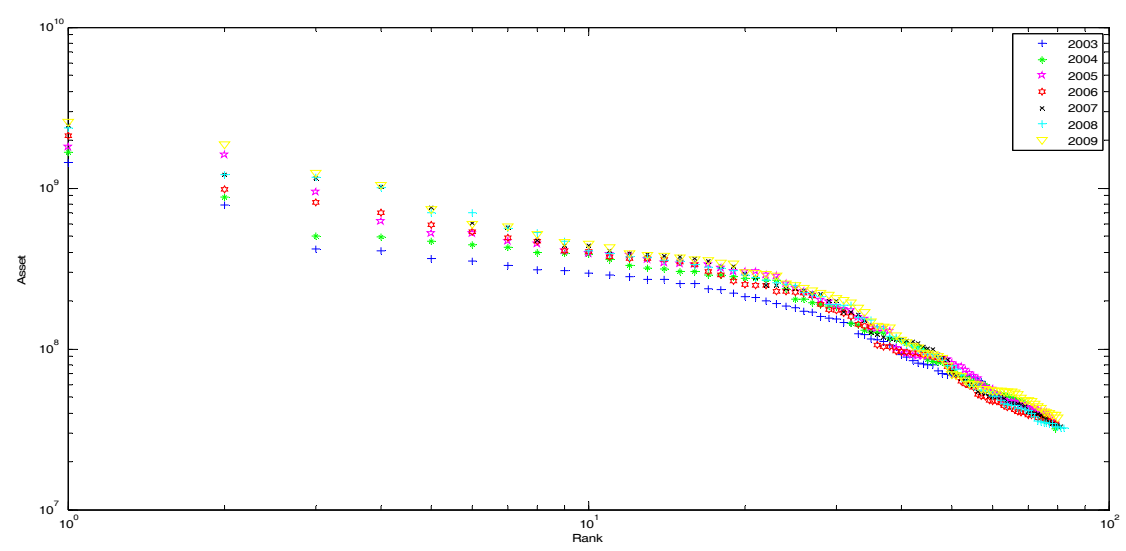

Figure 3. The rank distribution of asset 


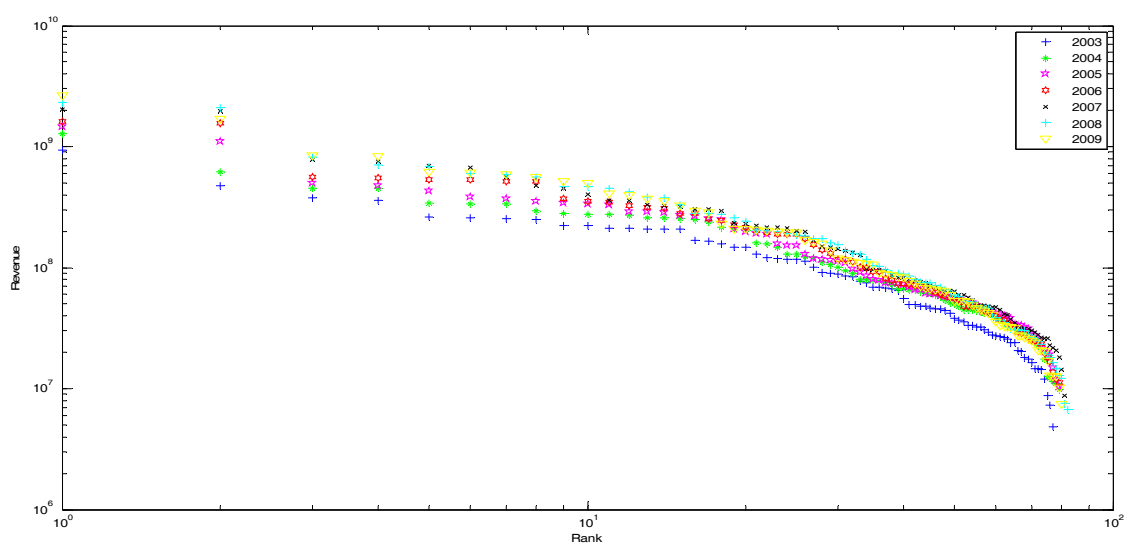

Figure 4. The rank distribution of revenue

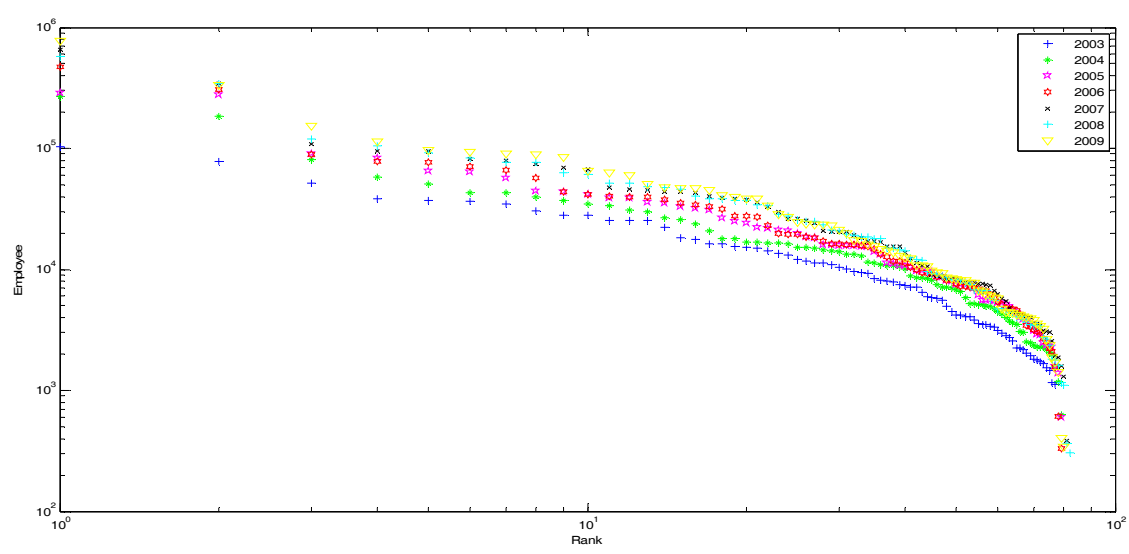

Figure 5. The rank distribution of employee

To explain the finding of our empirical evidence, the deviation may attribute to the grouping synergy on the business size. As we have mentioned, the large group usually rapidly extend their business scope by strategic alliances or mergers and acquisitions. This results in the business size to disperse over time.

Another reason to explain our result is the loosening China policy. Taiwan's government gradually lifted restrictions on the giant manufacturers to invest in China after 2000. Due to low-wage laborers and a large domestic market in China, the giant business groups gradually turn toward to China's market. This suggestion can be support by the rapidly increasing number of employee and the revenue in Table 1.

\section{Conclusion}

Previous research finds that Gilbrat's law fits the firm size distribution well but in the upper tail. Specifically, the empirical evidences find that there is a fatter tail for emerging ecomomies. During the last decade, because of the quick capital accumulation in the emerging markets, more a more companies in the developing countries got rapid growth by merging other companies and strategic alliance. The current trend results in many giant business groups in the developing countries. This paper uses the size of business groups instead of individual firms as our sample to study the business size distribution. Our goal is to examine whether it is one of the reason to explain the deviation of the Gilbrat's prediction for the developing countries.

Using the empirical evidence of Taiwan's large business groups, our study finds that the group size distribution is fatter-tailed and gradually deviated from the Zipf's Law during this decade. Our empirical evidence suggests the result may due to the rapidly extension on the giant business groups. The law of proportional effect is violated for the non-financial business in Taiwan. Specifically, the large business entities have greater growth rate. We suggest that the results may because they usually extend their scope by strategic alliance or mergers. Although we do not provide explicit evidence to support this conjecture, the issue is of interest for further research. 


\section{Acknowledgements}

The authors thank the editor and an anonymous referee for their helpful comments and suggestions. Remaining errors and weakness are the author's responsibility.

\section{References}

Axtell, R. L. (2001). Zipf distribution of U.S. firm sizes. Science, 293, 1818-1820. http://dx.doi.org/10.1126/science.1062081 PMid:11546870

Fujiwara, Y., Aoyama, H., Guilmi, C. D., Souma, W., \& Gallegati, M. (2004). Gibrat and Pareto Zipf revisited with European firms. Physica A, 344, 112-116. http://dx.doi.org/10.1016/j.physa.2004.06.098

Gabaix, X., \& Landier, A. (2008). Why has CEO pay increased so much? Quarterly Journal of Economics, 123, 49-100. http://dx.doi.org/10.1162/qjec.2008.123.1.49

Hall, B. H. (1987). The relationship between firm size and firm growth in the US manufacturing sector. The Journal of Industrial Economics, 35, 583-606. http://dx.doi.org/10.2307/2098589

Hernandez-Perez, R., Angulo-Brown, F., \& Tun, D. (2006). Company Size Distribution for Developing Countries. Physica A, 359, 607-618. http://dx.doi.org/10.1016/j.physa.2005.04.027

Kang, S. H., Jiang, Z., Cheong, C., \& Yoon, S. M. (2011). Changes of firm size distribution: The case of Korea. Physica A, 390, 319-327. http://dx.doi.org/10.1016/j.physa.2010.10.007

Khanna, T., \& Ravkin, J. W. (2001). Estmating the Performance Effects of Business Groups in Emerging $\begin{array}{lllll}\text { Markets. } & \text { Strategic } & \text { Management }\end{array}$ http://dx.doi.org/10.1002/1097-0266(200101)22:1<45::AID-SMJ147>3.0.CO;2-F

Leff, N. H. (1978). Industrial Organization and Entrepreneurship in the Developing Countries: The Economic Groups. Economic Development and Culture Change, 26, 661-675. http://dx.doi.org/10.1086/451052

Luttmer, E. G. J. (2007). Selection, Growth, and the Size Distribution of Firms. Quarterly Journal of Economics, 122, 1103-1144. http://dx.doi.org/10.1162/qjec.122.3.1103

Okuyama, K., Takayasu, H., \& Takayasu, M. (1999). Zipf's Law in income distribution of companies. Physica A, 269, 125-131.http://dx.doi.org/10.1016/S0378-4371(99)00086-2

Stanley, M. H. R., Buldyrev, S. V., Havlin, S., Mantegna, R. N., Salinger, M. A., \& Eugene, S. H. (1995). Zipf plot and the size distribution of firms. Economics Letters, 49, 453-457. http://dx.doi.org/10.1016/0165-1765(95)00696-D

Sutton, J. (1997). Gibrat's Legacy. Journal of Economic Literature, 35, 40-59.

Zhang, J., Chen, Q., \& Wang, Y. (2009). Zipf distribution in top Chinese firms and an economic explanation. Physica A, 388, 2020-2024. http://dx.doi.org/10.1016/j.physa.2009.01.027

Zipf, G. K. (1949). Human Behavior and the Principle of Least Effort. Cambridge: Addison-Wesley.

\section{Notes}

Note 1. To summarize Leff's (1978) and Khanna and Ravkin's (2001) definitions, a business group can be defined as an entity which contains multiple firms which are legally independent but are bound together by a common core controlling board which may be formal or informal.

Note 2. Zipf (1949) first suggests that the firm size distribution should follow the Pareto distribution with $\beta$ closed to 1 . Although debatable, this claim is confirmed by a lot of following research, such as Okuyama et al. (1999), Fujiwara et al. (2004), Luttmer (2007), Gabaix and Landier (2008) among others.

\section{Copyrights}

Copyright for this article is retained by the author(s), with first publication rights granted to the journal.

This is an open-access article distributed under the terms and conditions of the Creative Commons Attribution license (http://creativecommons.org/licenses/by/3.0/). 